\title{
Successful Pregnancy Outcome by Repeat Cesarean Section and Herniorrhaphy in a Case of neglected ruptured Incisional Hernia
}

\author{
${ }^{1}$ Savita Rani Singhal, ${ }^{2}$ Neetu Sangwan, ${ }^{3}$ Smiti Nanda, ${ }^{4}$ Suresh Kumar Singhal
}

\begin{abstract}
Objective: Gravid uterus with incisional hernia is rarely encountered complication. Aim is to report a case of pregnancy with ruptured incisional hernia.
\end{abstract}

Case report: A 35-year-old woman, gravida three, para two presented at 30 weeks of gestation with ruptured abdominal incisional hernia. She had previous two emergency cesarean sections done for contracted pelvis, 3 and 2 years back, respectively. Emergency herniorrhaphy was done. Postoperative period was uneventful and pregnancy advanced well without complication. At 37 weeks of gestation, she had elective cesarean section with bilateral tubal ligation. She delivered a healthy female baby of $2.5 \mathrm{kgs}$ and the postoperative period was uneventful.

Conclusion: If the woman was aware and had come earlier during antenatal period; she would have been put on conservative management (bed rest, binder, etc) which might had prevented rupture of the hernia and further the emergency herniorrhaphy which is additional risk factor for the mother and the baby.

Keywords: Pregnancy, Incisional hernia, Rupture.

How to cite this article: Singhal SR, Sangwan N, Nanda S, Singhal SK. Successful Pregnancy Outcome by Repeat Cesarean Section and Herniorrhaphy in a Case of neglected ruptured Incisional Hernia. J South Asian Feder Menopause Soc 2014;2(1):50-51.

Source of support: Nil

Conflict of interest: None

\section{INTRODUCTION}

Gravid uterus with incisional hernia is rarely encountered complication of abdominal wall closure. Cesarean section accounts for $3.1 \%$ of all cases. ${ }^{1,2}$ It is a potentially serious situation with adverse maternal and fetal risks such as incarceration, strangulation, preterm labor, intrauterine

\footnotetext{
${ }^{1}$ Professor, ${ }^{2}$ Assistant Professor, ${ }^{3,4}$ Senior Professor

1-3Department of Obstetrics and Gynecology, Pandit Bhagwat Dayal Sharma Postgraduate Institute of Medical Sciences Rohtak, Haryana, India

${ }^{4}$ Department of Anesthesia, Pandit Bhagwat Dayal Sharma Postgraduate Institute of Medical Sciences, Rohtak, Haryana, India
}

Corresponding Author: Savita Rani Singhal, 14/8FM, Medical Campus, Rohtak, Haryana, India, Phone: 00911262213643 e-mail: savita06@gmail.com growth restriction, accidental hemorrhage, intrauterine fetal death, rupture of the lower uterine segment, dysfunctional labor, postpartum hemorrhage, and burst abdomen. Here, we are reporting a case of pregnancy with ruptured incisional hernia.

\section{CASE REPORT}

A 35-year-old woman, gravida three, para two presented at 30 weeks of gestation with ruptured abdominal incisional hernia. Her first and second pregnancies were terminated by emergency cesarean section done for contracted pelvis, 3 and 2 years back, respectively. She denied any history of postoperative fever, prolonged hospital stay, or wound complications in those pregnancies. About 8 months after the second cesarean section, she developed incisional hernia for which she never consulted any doctor. General physical examination showed short stature woman with moderate anemia. Her cardiopulmonary status was normal with a pulse rate of 88 beats per minute and blood pressure was 120/70 mm Hg. On per abdominal examination, abdomen was uniformly distended. There was a broad longitudinal infraumbilical scar with overlying skin very thin and a defect of $5 \times 3 \mathrm{~cm}$ over the lower part of scar with skin and rectus sheath deficient over this. The uterus was visible through the defect with serous discharge from this site.

On palpation, the uterus was enlarged to 28 weeks size and fetal parts were palpable. Ultrasound revealed $28 \pm 2$ weeks alive fetus in longitudinal lie with adequate liquor and no gross congenital malformations. Emergency herniorrhaphy was done and her postoperative period was uneventful (Fig. 1). She had regular antenatal checkup and elective cesarean section with bilateral tubal ligation was done at 37 weeks delivering a healthy female baby of $2.5 \mathrm{~kg}$. Healing of wound occurred by primary intention. Postoperatively, both mother and baby did well and discharged after 2 weeks in a good condition.

\section{DISCUSSION}

Incisional hernia complicating gravid state is rarely encountered in obstetrics; ruptured incisional hernia is even rarer. This is due to the fact that by the time uterus becomes 


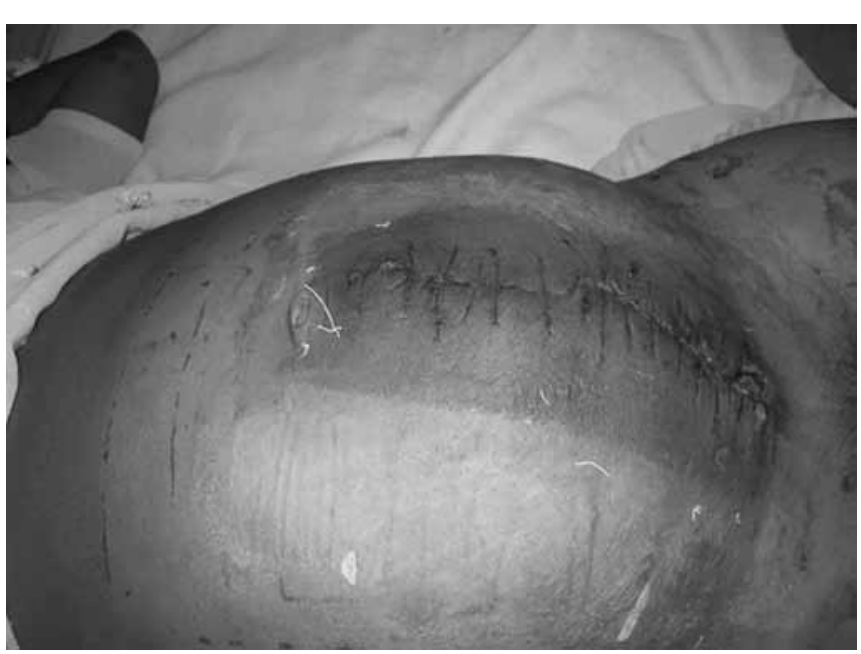

Fig. 1: Recent abdominal scar with gravid uterus

abdominal organ it is sufficiently large to enter the hernia sac. $^{2,3}$ Various predisposing factors for this morbid condition are midline incision, the need for additional operative procedures, antibiotic administration longer than usual with more potent antibiotics, presence of postoperative abdominal distension, intra-abdominal sepsis, residual intra-abdominal abscess, wound infection, wound dehiscence, postoperative fever, and healing of previous scar by secondary intention. ${ }^{2,4}$ The women in above mentioned case did not have any of the above mentioned conditions except for previous two cesarean sections by midline incision. She developed incisional hernia 8 months after the last cesarean and conceived in the mean time and did not take any medical advice for it. The management of pregnancy with the incisional hernia is mainly conservative with bed rest and abdominal binder as enlarged uterus may hinder optimal herniorrhaphy and further enlargement with advancing gestation may disrupt the hernia repair. Moreover, there are inherent risks of anesthesia and surgical intervention during pregnancy. ${ }^{2-4}$ If patient does not take proper rest, then hernia may rupture which occurred in the present case due to increase in the distension of the abdomen and negligent attitude of the woman.

Antenatal herniorrhaphy is required in case of incarceration, strangulation, burst abdomen or large incisional hernia where risk of incarceration overweighs the risk of continuing the pregnancy without herniorrhaphy. Emergency herniorrhaphy had to be done in this woman due to rupture of the hernia. The mode of delivery in women with incisional hernia is controversial. A cesarean section in a woman with large incisional hernia offers a means of hernia repair during the operation, while a vaginal birth provides time for healing and a delayed repair can be scheduled. ${ }^{4}$ In this case, the lady was multipara with previous two cesarean sections, so elective cesarean section with bilateral tubal ligation was done. Had the woman came earlier during antenatal period, she would have been put on conservative management (bed rest, binder, etc.) which might had prevented rupture of the hernia and further the emergency herniorrhaphy which is additional risk factor for the mother and the baby.

\section{REFERENCES}

1. Makama JG, Odigie VI, Yusufu LM, Ameh N. Herniated gravid uterus: clinical course and result of treatment. Ann Afr Med 2007;6(4):197-199.

2. Saha PK, Rohilla M, Prasad GRV, Dhaliwal LK, Gupta I. Herniation of gravid uterus: report of two cases and review of literature. Med Gen Med 2006;8(4):14.

3. Roy KK, Agarwal S, Banerjee K, Kumar S, Chanana C. Gravid uterus in an incisional hernia leading to burst abdomen. Int $\mathrm{J}$ Gynaecol Obstet 2005;5(1):2-5.

4. Rao RS, Shankaregowda HS. A case of herniated gravid uterus through a laparotomy scar. Indian J Med Sci 2006;60(4):154-157. 